\title{
ECONOMIC STATUS OF THE AGED POPULATION: AN OVERVIEW OF INDIAN LITERATURE
}

\author{
Dr. R. HARIHARAN ${ }^{1 *}$
}

${ }^{*}$ Assistant Professor, Department of Economics, Government Arts College, Udhagamandalam [Deputed from Annamalai University]

\section{*Corresponding Author: -}

\begin{abstract}
: -
This paper reviews the economics status of aged persons in India. Aged Persons will be one of the major policy concerns of the twenty-first century. Population ageing will affect every single individual of the society in many ways. The review analysed economic status of the aged persons based on their family status, income status before and after retirement, saving and borrowing status of the aged persons in India. As the country is ageing, this will affect the economy, because the economic needs of the society will be different in an ageing society. Every ageing nation suffers from over dependency and lesser participation of younger Human Resources in productive processes. It is felt that the retired ageing populations start using the nation's resources for social security needs, which is estimated to be a big burden on the exchequer of the state. Thus, the impact of ageing on Indian economy is multi-faced, which includes production, consumption, labour force and social expenditure on retirement. The developed world has already witnessed this and is looking for options to overcome this problem. However, this trend clearly reveals that aged persons will be a very big issue to the future society and vast resources need to be directed towards the support and care of the aged population. Thus, the present paper suggests the researchers in the field of aged population and their economics status to bring various researches for improving their economics status and assure the social status of aged population.
\end{abstract}

Keywords: Aged population, Ageing, elderly, economic condition and economics status.

\section{(c) $(\$)$}




\section{INTRODUCTION}

Population ageing is expected to have serious problem on local, regional, and global economies. Due to rising old-age dependency ratio of elderly to working-age population, the burden of caring for the elderly is shifting from families to government, businesses, unions and other institutions as well as to the elderly themselves through personal savings for old age. In 2001 ageing population (60 years and over) in the World comprises around 10 per cent of the total population and is projected to increase to 22 per cent by 2050 .

Population ageing will affect every single individual of the society in many ways. India too, faces many demographic problems in the shape of the rising profile of the aged population. Over the past fifty years, mortality rates have declined in developing countries raising the average life span from around 41 years in 1950 to almost 62 years in 1990. According to WHO, this average life span is expected to reach 70 years by 2050 . One of the main features of the world population in the elderly population in the $20^{\text {th }}$ century has been a phenomenal increase in both the developed and developing countries. Approximately among the 580 million elderly (60 years and above) in the world, around 355 million live in developing countries. The number of elderly world wide by 2020 is expected to cross 1000 million with over 700 million of them in the developing countries. The population of those who are 60 and above constituted 5.66 per cent of the total population in 1951 in the case of India. India had 25 million persons over 60 years in 1961 and 33 million in 1971 . The figure rose to 40 million in 1981. In 1991, the figure further increased to 56 million constituting 6.5 per cent of the total population. The population of the aged was predicted to become 76 million by 2001, forming 7.6 per cent of population and nearly one-seventh of the world elderly. By 2020, the number may rise to 124 million which means 11 per cent of the population will be less than 15 years. It is expected that in 2025 their population will be more than 175 million.

This is likely to have a bearing on their economic activities. Poverty and loneliness further add to the problem of elderly care by rendering them even more vulnerable. Traditionally, in India, the most common form of family structure was the joint family. The extended family consisted of at least two generations living together and this arrangement was usually to the advantage of the elderly as they enjoyed a special status and power. But with growing urbanization and depending on the availability of jobs, children are moving out of the extended family set-up, leaving the 'empty nest' and establishing their own nuclear families. In the coming years, the elderly population will phenomenally grow in numbers and at the same time, the family size is reducing, more so in the urban areas. In the absence of traditional caregivers, due to the disintegration of the joint family and women moving out of the household, the elderly have become a vulnerable group, needing care and attention.

\section{Economic Status of the Aged Population}

Indian economic development looks at youth and their involvement in the development process. May be this is because young are more informed and expected to participate actively and productively for longer years. Therefore the programs of support and of economic products appear to have been directed to the youth and the adult not for the aged. As the country is ageing, this will affect the economy, because the economic needs of the society will be different in an ageing society. Every ageing nation suffers from over dependency and lesser participation of younger Human Resources in productive processes. Industries suffer from short supply of productive labour. It is felt that the retired ageing populations start using the nation's resources for social security needs, which is estimated to be a big burden on the exchequer of the state. Thus, the impact of ageing on Indian economy is multi-faced, which includes production, consumption, labour force and social expenditure on retirement.

Coming to the issue of productivity, the older workers are considered to be less productive than their younger counterparts. Researchers believe that absenteeism is more among the older workers due to medical reasons and therefore their productivity tends to decline. With technology advancing faster in every production process, the ageing of the labour force will speed up the obsolescence of human capital. Although retraining of the older workers is suggested to overcome this problem, it is very difficult to motivate older workforce to unlearn and relearn and retrain new techniques and skills. Employers too, prefer to induct youth and fresher from the universities and management institutions at a cheaper cost than retraining their older and shortly retiring workers.

The other economic dimension of the ageing of population, although it is not immediately visible in India is, as the ageing work force is retiring; there will be fewer younger workers to replace them. This will create high demand for labour leading to increasing wages. It will reach a situation that the cost of labour will make the production not viable. The developed world has already witnessed this and is looking for options to overcome this problem. Given this, the paper analyses the existing research in the field of aged population and their economic status in India.

\section{Literature Review}

The literature in the field of aged population is very large at national and international level. The present study makes a review of the important works at national level to understand the issues and thereby to suggest new research avenue for addressing the issues.

According to Jamuna (1998), Ninety per cent of older persons live and work in the informal sector and 80 per cent of older people live in rural areas. If they live with children in the village, the care that older people get depends on the economic status of the children as well as their own contribution to family income. Since a great majority of rural old people live in poverty and there is almost no social security from the state, the presence of older persons in the family adds to the family's financial difficulties. When older people accompany their children to the city, the situation could be worse, since the older person's ability to contribute to family income would be diminished in the city environment.

Panda (1998) investigated the financial system of care and support for aged mainly focusing on the living arrangements, in a rural setting in Orissa. He felt that increased poverty and economic stress in rural Orissa was likely to erode the 
traditional family care and support for the aged women in particular, because of their limited access to property right and income. He suggested that there was a need for the government to pay special attention to the support and care for aged women. The most immediate step was to provide social security to targeted aged women who lived alone. The provision of social security for the aged in India is far less than needed and retirement benefits were applicable to less than the 10 per cent of the workforce in the formal sector.

Barai's (2001) study on "A profile of the elderly in the slums of Bangalore," depicted the demographic characteristics of the elderly. This study showed a large percentage belonged to 60 to 64 years age group compared to old-old. Forty-four per cent were widowed, where in women were more than men. Most of the elderly respondents ( 70 per cent) belonged to the scheduled caste and scheduled tribes. They did not have any income of their own and one third of them were bread winners for their families. This study revealed that 37 per cent of the elderly being drawn into the unorganized sector labor force due to illiteracy and 38 per cent were working as coolies, 21 per cent as construction workers, 21 per cent mostly women roll agarbatties. Regarding earnings, 12 per cent of the households got an income will be low Rs. 500 per month. Fifty-five per cent of health problems ranged from regular to normal problems, and 6 to 7 per cent of women suffered from chronic backache and asthma.

Audinarayana et al. (2002) in their rural study of Coimbatore district - among 558 elderly persons belonging to four villages - observed that about one-third of widowed, a greater per cent were illiterates. About fifty per cent were working and had independent earnings. Gender differentials in these regard were noteworthy. The proportion of widowed, illiterates, not-working and thereby, not earning any income were significantly higher among females compared to males. Development has both positive and negative impact on the elderly. Development creates more employment opportunities in formal economy which means fewer employment opportunities for elderly men but more work opportunities for elderly women. Interviews with older women reveal active participation in work in rural and urban areas. Despite various ailments and locomotive disabilities, older women contribute to their families and communities in many meaningful ways - cook, clean, fetch water, take care of grandchildren, and make repairs (UNFPA, 2002).

Kumar et al. (2005) study explained among 980 elderly persons belonging to selected rural areas of three northern states, namely, Uttar Pradesh, Madhya Pradesh and Bihar, noticed that a greater percentage of the male elderly (80\%) were currently married as against more than half of the female elderly. Both social and economic status of the elderly significantly (based on chi-square test) associated with their caste background, i.e., higher the caste group higher would be the socio-economic status and vice-versa. As expected, the proportion of elderly who have some education (primary and high school level) was significantly higher among males as well as among young-old as against to those females and old-old. Routine work of the elderly (same as before, less physical activities but more supervision, only supervision and nothing) was significantly associated with their gender background and current age.

According to Ajomale (2006), the aged persons living in nuclear families are forced to participate in income generating activities to maintain livelihoods as well as they are likely to save some money for emergencies, because most of them would be heads of the households and majority of the unmarried children would be either unemployed or continuing their studies. Under these circumstances, elderly persons living in joint families would have less personal income and thereby, have less saving capacity. Moreover, in such families, whatever income the aged earn would be most probably be used for their personal purposes rather than spending for the family.

Higher proportion of elders increases the old age dependency ratio, implying a rise in the number of retirees relative to that of workers. Recent census results reveal a decline in the labour force participation among the 60+ age group. Such declines in labour force participation may be due to lack of employment opportunities for the elderly or due to obsolescence of skills or due to the expansion of the old age support systems in the form of pension and retirement programmes (Vaidyanathan $K, 2006$ ).

Vijayakumar (2006) mentioned that the basic concept of social security is not new in India. Traditionally, a sort of moral economy existed to provide security to older destitute and other vulnerable groups in society. However, gradually, traditional support systems are disappearing, and state-based social security systems have come into existence. Under standardized economic security policies, government is covering retirement benefits for those in the organized sector; economic security benefits for those in the unorganized sector; and old-age pension for rural aged.

The study conducted 325 women elderly persons belonging to eleven villages of Dindigul district in Tamil Nadu. The highlighted that a greater proportion were illiterates $(80 \%)$, half of them were working in agricultural and related occupations at the time of survey $(50 \%)$, slightly more than fifty per cent were in widowhood status, getting low and moderate personal income as well as belonged to low and average monthly family income brackets (45\% \& $43 \%$ and $50 \% \& 43 \%$, respectively). Less than half of them had the habit of betel leaves taking (47\%), and about one-fifth chewing tobacco (20\%) (Pappathi, 2007).

Devi et al. (2008) study conducted in rural and urban areas (991 and 200 elderly persons, respectively) of two districts (Ernakulam and Kozhikode) in Kerala state. About 34 per cent of the aged do not have any asset, 37 per cent had liquid asset (those who had enough money) and 29 per cent had only immovable assets. Among those with liquid assets, 19 per cent had only cash and 81 per cent had both cash and property. In the case of women, these proportions did not vary across the rural and urban areas. Conversely, it was found that the proportion of women with immovable property was high in the urban areas than in rural areas. Across the religious groups, it was noted that the proportion of men who had liquid asset was observed as much higher among Christians (67\%) and the lowest among the Hindus (46\%). On the other hand, the proportion of women who had immovable asset was the lowest for Christians in the case of both men and women. It was also found that the financial status of both men and women above the age of eighty years was worse off than their counterparts in the lower age groups. Among illiterate men, about the half of them had immovable assets, whereas slightly more than fifty per cent of women did not have any financial means. However, education made a big 
difference in having liquid asset. For instance, among those with at least 10 years of schooling a greater per cent (88\%) of men and three-fifths of women had liquid asset.

Based on primary data collected from random sample of 8 per cent of aged population in Kollidam comprising 75 male and 60 female (Hariharan, 2009) have concluded that the mean household income is two times higher for aged in joint family and it is interesting to note that old-old has maximum income compared to young-old. Income obtained from other sources like crop income, house rent etc., and was found in higher share in the small families. The study clearly indicates that aged people are economically independent as their share in family income is higher in both nuclear and joint families. The aged persons' health status was maintained due to their savings.

Panda (2008) observed an empirical study in four districts of Madhya Pradesh (958 elderly women - two-thirds were from rural areas), that 65 per cent were widowed, 73 per cent were staying in joint / extend families and 11 per cent elderly women were staying alone. An overwhelming proportion of the women elderly were illiterate (96\%) and hardly 4 per cent were just literate. 60 per cent of the respondents housewives. Among the workers, 43 per cent were daily wagers, 12 per cent were self-employed, 9 per cent were agricultural workers and 3 per cent were salaried employees. Income distribution showed that about onefourth each of the respondents earning low and moderate incomes (50-250 and 251$500)$ and the rest fifty per cent comparatively better income (550-8000).

Swarnalatha (2008) study revealed that a greater proportion of women (88\%) were illiterates, whereas one-tenth had primary level of education. 71 per cent of the elderly were widowed, more than two-fifths were working as agricultural labourers and a greater percentage of them were either partially or fully dependent. About two-thirds each of elderly women's annual income was less than 11,000 (below poverty line), belonged to low socioeconomic status and spent their leisure time activity mostly with peer group.

Mariacristina et. al. (2009) says that the risk of outliving one's expected lifespan has a large effect on the elderly's saving behavior. Medical expenses increasing with age and permanent income leads to proper old age savings for the richest. When life expectancy is decreased the rich retirees are less likely to survive to very old age and face very large medical expenses. This has a large effect on their level of savings. On the other hand, removing medical expenses altogether greatly reduces total savings, which were used to insure against both life span risk and medical costs. For this reason, the change in life expectancy has a larger impact in percentage terms then when there are no out-of-pocket medical expenses. Rahman et al., (2009) study provides a comprehensive analysis of gender differences in economic support and well-being based on findings of interviews conducted with 743 elderly from rural area under Naogaon district, Bangladesh. The study examine multiple economic indicators, including sources of income, receipt of financial support, income levels, ownership of dwelling and satisfaction with adequacy of income. Results show substantial variation in gender differences across indicators and provide an important qualification to widely held views concerning the globally disadvantaged position of older women. Whereas men tend to report higher levels of income than women, there is also a quite gender difference in housing characteristics, dwelling ownership or reports of satisfaction with the adequacy of income. Findings need to be significantly utilized in developing suitable programs addressing the case of elderly of the developing countries as well as Bangladesh.

Yesudian and Singh (2009) study described the elder's (60+) work participation rate is decreasing over the years according to various rounds of census. In economic activity elderly men's participation is declining whereas the elderly women's participation is increasing both in rural and urban areas. Looking back at the low literacy level almost 50 years ago in India, one wonders what kind of occupation these women might be involved in. Periodical National

Sample Surveys (NSSO) provide an ample opportunity to analyse elderly population's work participation and why, how these elder's are working. This paper is an attempt to explore the elderly person's work participation over the decades and also explores the background characteristics of these elderly workers. It also finds some determinants which contribute to gender-specific work participation at this age.

Benjamin, et al., (2010) say that more than half of the respondents are financially independent while 44 per cent depend on their children, sons or daughters-in-law, friends, neighbours or government financial assistance. Age and employment status were significant predictors of financial independence across all ethnic models. There are different predictors of financial dependency by ethnic group and the result calls for different intervention strategies for the various ethnic aged in achieving financial independence in old age.

Hariharan and Malathi (2011) study was based on primary data collected from 120 aged persons, comprising of 60 males and 60 females with equal representation in three age groups, viz., 60-69 years, 70-79 years and 80 years and above. Regarding different economic aspects of aged persons (viz., monthly income, savings and expenditure for different purposes of day-to-day needs) of a town in Karaikal region found that earning capacity gradually decreases as age goes up. It reduces to 48.3 per cent of the income they earned, before the age of 60 years. The second objective is to analyze the variations in the expenditure pattern of aged population according to their age. It is interesting to observe that as age increases food expenditure decreases whereas it is reverse with respect to the medical expenditure.

Hariharan et al., (2011) have shown that average income of the aged persons is comparatively higher among those living in nuclear families as compared to those living in joint families. This indicates that aged persons have greater economic security in nuclear family compared to joint family. Aged persons prefer the deposit in the government sector, which are more secured than the private sector (Chit fund). Moreover, aged persons from nuclear families appear to be given more importance to the habit of savings. The overall expenditure also appears to be comparatively higher among those elderly residing in nuclear families than among their joint family counterparts. Children are the primary monetary source to the elderly for both food and non-food expenditure, irrespective of their family system. 


\section{Conclusion}

From the studies reviewed above, it is concluded that the major sources of income of elderly are wages and salaries, including self-employment, investment and rent, retirement pension and other social security benefits. Distinguishing features of the incomes of the elderly people compared with those of the younger adults are the low proportion derived from wages and salaries and low labour force participation. These are the primary sources of inequality between the elderly and young. The overall expenditure also appears to be comparatively higher among those elderly residing in nuclear families than among their joint family counterparts. Children are the primary monetary source to the elderly for both food and non-food expenditure, irrespective of their family system. Technological change has been reported to have undesirable outcomes- increased stress due to faster pace of work, the increased obsolescence of older workers and reduction of face to face interaction and weakening of family and other social ties. Since different age groups have different economic needs, a country's economic characteristics may be expected to change as its population ages. Particularly the ageing has relation with the earnings, employment, savings and expenditure of the person.

Besides a study found that labour force participation may be due to lack of employment opportunities for the elderly or due to obsolescence of skills or due to the expansion of the old age support systems in the form of pension and retirement programmes. Under standardized economic security policies, government is covering retirement benefits for those in the organized sector; economic security benefits for those in the unorganized sector; and old-age pension for rural aged. One paper is an attempt to explore the elderly person's work participation over the decades and also explores the background characteristics of these elderly workers. It also finds some determinants which contribute to gender-specific work participation at this age. Thus, the studies has analysed the economic condition of aged population in Indian scenario where in there are different predictors of financial dependency by ethnic group and the result calls for different intervention strategies for the various ethnic aged in achieving financial independence in old age.

\section{References}

[1].Ajomale, Olayinka (2006) "Country report: Ageing in Nigeria - Current State, Social and Economic Implications", Paper presented in ISA's XIV World Congress of Sociology: Sociology of Ageing, held at Durban, South Africa.

[2].Audinarayana, N., J. Sheela and N. Kavitha, (2002), “Are the Elderly Women the Most Deprived among the Deprived? A Micro Level Investigation in Rural Tamil Nadu", in Ageing Indian Perspectives. L. Thara Bhai (Ed.). New Delhi: Decent Books, pp. 247262.

[3].Benjamin Chan Yin-Fah, Tengku Aizan Hamid, Jariah Masud and Laily Paim (2010),

[4]. "Predictors of Financial Dependency in Old Age in Peninsular Malaysia: An Ethnicity Comparison", Asian Social Science, 6(6):54-62.

[5].Devi, D., Radha, A. Asharaf, Nandini Das, S. Santosh, and S. Surendra, (2008), "Economics of Ageing: A Study Based on Kerala", New Delhi: Serials Publications.

[6].Kumar, Alok, Haruo Sagaza, K. N. S. Yadava, and Brijesh P. Singh, (2005), "Socioeconomic and Demographic Characteristics of Elderly in Rural Northern India", in The Elderly: Emerging Issues. M. A. Sattar and Samad Abedin (Eds.). Dhaka: The Bangladesh Association of Gerontology, pp. 31-64.

[7].Hariharan, R. (2009), "Economic and Health implications of Aged Population", Annamalai Economic Paper, 5:6-12.

[8].Hariharan .R and N. Malathi, (2011), "Economic Status of Aged Population in Urban

[9].Setting of Karaikal Region", National Seminar on Ageing: Issues and Strategies, Chidambaram; Annamalai University, Jan11-12.

[10]. Hariharan .R, N. Malathi and N. Audinarayana, (2011), "Family System and Economic Aspects of Aged Persons in a Rural Setting of Tamilnadu", in K.N.S. Yadava and Alok Kumar (Ed.), Ageing Some Emerging Issues, Profiles, Trends and Policy Perspectives, New Delhi: Manak Publications, pp.38-54.

[11]. Jamuna, D., (1998), “Challenges of changing socio-economic and psychological status of the aged”, Research and Development, 5(1).

[12]. Mustafizur RahmanE.M , Md. Ismail Tareque and Md. Mostafizur Rahman (2009), “Gender Differences in Economic Support, Wellbeing and Satisfaction of the Rural

[13]. Elderly in Naogaon District, Bangladesh”, Indian Journal of Gerontology, Vol. 23 (3), pp 343 -357.

[14]. Panda, Pradeep Kumar (1998), "The Elderly in Rural Orissa”, Economic and Political Weekly, 34(23):1545-1550.

[15]. Panda, Archana, Kaushik, (2008), "Elderly Women in Madhya Pradesh: Condition and Challenges", HelpAge India Research \& Development Journal, 14(2): 11-19.

[16]. Pappathi, K., (2007), “Ageing: Scientific Perspectives \& Social Issues”, New Delhi: A.P.H Publishing Corporation.

[17]. Princy Yesudian and Singh (2009), "Working Elders in India: A Gender Specific Situation Analysis", Indian Journal of Gerontology, Vol. 23 (1), pp 42 -57.

[18]. Swarnalatha, N., 2008. "A Study on Health Problems of Aged Women in Rural Areas of Chittore District", HelpAge India Research \& Development Journal, 14(1): 16-23.

[19]. UNFPA (2002). Population Ageing and development: Social, health and gender issues. Population Development Strategies,No.3. Working Elders in India 57.

[20]. Vaidyanathan, K. (2006). Social and Health Aspects of Ageing in India: Implications for the National Policy on Older Persons (NPOP), IIPS international Conference.

[21]. Vijayakumar, (2006), "Economic Security for the Elderly in India: An Overview”, Journal of Aging \& Social Policy, Vol.15. 